\title{
Research on Mechanism of Government-led Regional Tourism Cooperation
}

\author{
Yadi $\mathrm{HU}^{1, \text { a }}$, Bing $\mathrm{HAN}^{2, \mathrm{~b}}$ \\ ${ }^{1}$ Graduate School of Agricultural University of Hebei Province,Baoding,China \\ ${ }^{2}$ Graduate School of Agricultural University of Hebei Province,Baoding,China
}

Keywords: Policy; Tourism Development, Preservation of Historic Site; Regional Cooperation; Mechanism

\begin{abstract}
In development process of market economy, seeking regional cooperation and common development has become increasingly general consensus instead of studying tourism in a narrow scope. Regional cooperation has become an irresistible trend for tourism development and expansion in different areas. However, a series of issues such as main body of cooperation and cooperation mechanism have arisen in the existing regional cooperation practice of tourism, which are worth discussing and solving. The Paper has proposed to establish conditions and corresponding measures required by complete and thorough regional tourism cooperation mechanism based on research of corresponding scholars.
\end{abstract}

\section{Introduction}

With rapid economic development in our country since the 1990s, material standard of living has been continuously improved, leading to higher cultural demand. All local governments go with the stream to introduce a large number of policies and measures to support and encourage development of tourism. In some areas with favorable conditions, tourism has become important supporting point for economic development. Relations among tourism areas are becoming increasingly close, getting out of the restriction of individual and developing towards regional tourism cooperation. Whether from selection of travel destination by tourist or objective requirement for market operation of tourism or seeking proper development strategy by tourism itself or regional connection, line connection, traffic connection and products complementation, requirements of regional integration of tourism and enhancing regional economic strength by tourism multiplier effect are rationally proposed.

\section{Main Bodies of Regional Tourism Cooperation}

The existing research articles show most scholars define three kinds of main bodies of regional tourism cooperation, namely, government, enterprise and non-governmental organization. It is believed in the Paper that despite of different status and function in different time points of regional tourism development, the difference does not affect government to be the first main body of regional tourism cooperation. First, some disadvantages in government leadership can not deny the status of intergovernmental cooperation. The reason why some scholars think regional tourism cooperation shall be led by market with enterprise as the first main body is some disadvantages brought by governmental leadership. Relying on personal preference or transformation to vanity projects are not inevitable problems in governmental leadership, which are closely relevant to decision-making mechanism and whether administrative system is thorough. Moreover, market leadership will also bring some disadvantages such as vicious competition, repeated investment, ignorance of public interest, etc. Therefore, the conclusion can not be drawn that regional tourism cooperation shall regard enterprise as the first main body. What is more important is from current situation, regional tourism cooperation is the tourism cooperation mainly conducted among administrative regions, which is overcoming instead of intensifying administrative region segmentation. Second, main obstacle for regional tourism cooperation lies in systematic obstacle. 
Inter-governmental cooperation is to be enhanced to overcome the system. Chen Shengyong and Ma Bin (2004) pointed out in the analysis for regional cooperation that currently the biggest problem in economic areas including the Yangtze River Delta and the Pearl River Delta was administration in their own way with regional market division and local protectionism blocking free flow of economic resources and trans-regional economic cooperation. Under the circumstance of imperfect market mechanism and extremely unsound rule of law, obviously it is difficult to break systematic obstacle by only relying on the market force of private economic engagement coming from below. Therefore, a powerful regional government cooperation mechanism shall be established to promote regional economy integration relying on cooperation among governments. The above analysis also applies to development of tourism. From practice of regional tourism cooperation, the main obstacle with which it is confronted is systematic obstacle. Under the circumstance, development of regional tourism cooperation inevitably requires inter-governmental cooperation to eliminate these obstacles. Third, development of tourism is of highly public property in which governments play an important role in tourism development. Compared with other industries, tourism is special because it is not totally an economic industry, which undertakes many social undertaking functions. Development of tourism involves plenty of development, utilization and management of public resources and provision of public products (such as regional image improvement, destination marketing, public infrastructure, etc.). It is especially true for a country based on public ownership like our country, which makes government undertake not only the function of macroeconomic control in tourism industry but also the function of provision of tourism products and tourism production factors organization. The important status of government in tourism development is also embodied in regional tourism cooperation. Fourth, which is also the most fundamental is that inter-governmental cooperation has prominent "regional" characteristic while inter-enterprise cooperation is hardly "regional". In a sense, although governments are composed of officials with their own interests, but on the whole governments may be regarded as the representative of regional interests. It is not only because the mission is such but also because achievement assessment of government officials in reality is often related to regional development conditions. Regional cooperation conducted by tourism enterprises is mainly from their own interests rather than regional interests, that is, tourism enterprise cooperation is not highly "regional", which is decided by the nature of enterprise. Although the trend for now is enterprise shall undertake more social responsibility, enterprise shall follow the principle of profit maximization in essence. In our country, regional tourism cooperation has become a specialized research field. The reason why research of regional tourism cooperation is different from research of general tourism cooperation is because it is "regional". It lays emphasis on discussion of inter-regional tourism cooperation action from overall regional interests with government as the first main body of regional tourism cooperation. However, theoretically, enterprise shall be the most important main body in regional tourism cooperation, whereas government plays a more prominent role in regional tourism cooperation practice.

\section{Regional Tourism Cooperation Mechanism}

\section{Regional tourism cooperation}

In recent years, regional tourism cooperation in our country is flourishing with remarkable effect achieved, during which, however, some problems are exposed. Often regional tourism cooperation agreements (or similar provisions) are signed at the beginning of cooperation, but then become formalistic to develop, most of which end up in the situation existing in name only and failing to carry it through. Specific performance is to be bound by traditional enclosed development concept with inadequate awareness for the cooperative "great tourism, great development and great region" development concept. Existence of local protectionism gives rise to the trend of "cooperation without action" among regions in respect of tourism resources, tourism infrastructure, tourist source market share and other aspects. Resource development adopts respective systems with repeated construction for close attractions, resulting in unreasonable resource allocation. For the sake of respective interests, compete for tourist source to form vicious competition, disrupt market order. 
There is hardly any cooperation and communication among tourism enterprises with blocked of information and poor supervision from governments. Therefore, regional barriers still exist to some extent, resulting in slow progress of regional tourism cooperation. It is believed in the Paper that the root cause of the phenomenon is conflict between individual interests and collective interests of cooperation participants during regional tourism cooperation process. That is, there exists conflict between individual rationality and collective rationality. According to modern economics viewpoints, the solution to the problem is by designing a mechanism to reach collective rationality on the premise of meeting individual rationality rather than by government interference advocated by traditional economics.

\section{Establishment and improvement of regional tourism cooperation mechanism}

As a special pattern of manifestation of regional economy in our country, the phenomenon of "administrative tourism area" and "administrative area economy" have been embodied in regional tourism development to varying degrees. For example, many tourism areas often become representative of "interest area" of local government. Specific performance of "administrative tourism area" is local government becoming both constitutor and implementer of regional tourism development strategy and undertaking functions such as tourism industry management, tourism product organization, tourism image decoration and promotion and tourism marketing. Although governments have proposed the requirement of building "non-obstacle tourism area" from the aspect of regional cooperation to reduce obstacles to flow of regional tourism factors by administrative region factor, the phenomenon of "administrative tourism area" still affect the progress of regional tourism cooperation to varying degrees.

The ultimate objective of bounded rationality cooperation among main bodies of tourism cooperation is to achieve a win-win situation. However, in realizing the objective, both common interests and respective interests exist among cooperative main bodies. Due to uncertainty of cooperation environment, incomplete information, capacity of people to master, calculate and analyze environment and information and other limitation, "rationality" of people is bounded (Simon, 1957). Bounded rationality exists so that main bodies are always led by maximization of self- interests, probably leading to Inefficiency or low efficiency in cooperation of the whole region. Driven by opportunism, it may give rise to conflict between individual rationality and collective rationality during regional tourism cooperation.

Due to limitation of government management function, implementation of current regional tourism cooperation mostly manifests as government promotion and administrative encouragement. Practically, the process of managing tourism industry by governments is the process of decision-making according to tourism market information by governments. Therefore, whether governments have accurate and adequate information becomes the necessary condition for governments to manage correctly and make decisions scientifically. Market environment is complex and internal information of tourism enterprises is difficult to obtain with accuracy which give rise to poor supervision by governments on "cooperation without action" and opportunism in regional tourism among tourism enterprises.

\section{Tourism resources conditions and tourism resources being regional tourism cooperation}

Tourism resources are characterized by difference, sharing, and competitiveness. Difference in tourism resources can form complementation so as to generate synergy and complementary effect. Synergy effect means to improve overall value and benefit by mutual utilization of invisible assets of the whole and its components. Complementary effect is essentially an increase in number, which is by excavating unique real assets of all and fully combining and using them to improve overall value and benefit. Sharing of tourism resources means cross-regional distribution of resources, which is also characterized by non-excludability. Meanwhile, competition for resources in different regions may give rise to the tragedy of "common grazing". Therefore, development of sharing tourism resource objectively requires cooperation across regions to enhance development and protection for sharing resources and maintain sustainable development of resources. Competitiveness of tourism resources means little difference between resources among tourism areas with close attractive intensity to tourist source market, leading to intensified competition 
between tourism regions. For rational developers, the result of competition can only be loss at both sides. Therefore, cooperation based on competition may bring result benefiting both sides.

\section{Conclusion}

In a word, although regional tourism cooperation takes some cost which is mainly regional management and coordination expense, establishing thorough regional tourism cooperation mechanism is not only in favor of favorable partnership established in current and future regional tourism cooperation for all the areas to realize common interests of regional tourism cooperation, but also in favor of the realization of localized interests, tourism enterprise interests and other various interests. By regional cooperation, overall regional market demand is expanded, improving benefits for main bodies of cooperation. Regional cooperation breaks the original regional limitation with resources to be allocated optimally by market. Regional industrial scale expands continuously to form scale economy. Meanwhile, transaction cost decreases with formation of regional tourism cooperation organizations. The cost saved by decreased transaction expense and improved transaction efficiency is equivalent to benefits. Therefore, when planning tourism project and scheme in tourism subsystem of all the areas, follow rules, comply with trend and coordinate actively to promote market integration and optimize resource allocation. Establish thorough institutional system for regional cooperation to fully ensure interests of all parties as well as stable and sustainable development of their own and environment system.

\section{Reference}

[1] Geng, Y., Chen, J., Fu, R., Bao, G., and Pahlavan, K. (2015). Enlighten Wearable Physiological Monitoring systems: On-Body RF Characteristics Based Human Motion Classification Using a Support Vector Machine. PP(99), 1-16.

[2] Song, X., and Geng, Y. (2014). Distributed Community Detection Optimization Algorithm for Complex Networks. Journal of Networks, 9(10), 2758-2765.

[3] Pahlavan, K., Krishnamurthy, P., and Geng, Y. (2015). Localization Challenges for the Emergence of the Smart World, Access, IEEE, 3(1), 1-11.

[4] He, J., Geng, Y., Wan, Y., Li, S., and Pahlavan, K. (2013). A cyber physical test-bed for virtualization of RF access environment for body sensor network. Sensors Journal, IEEE, 13(10), 3826-3836.

[5] Lv Z, Tek A, Da Silva F, et al. Game on, science-how video game technology may help biologists tackle visualization challenges[J]. PloS one, 2013, 8(3): 57990.

[6] Su T, Wang W, Lv Z, et al. Rapid Delaunay triangulation for randomly distributed point cloud data using adaptive Hilbert curve[J]. Computers \& Graphics, 2016, 54: 65-74.

[7] Jinyu Hu, Zhiwei Gao and Weisen Pan. Multiangle Social Network Recommendation Algorithms and Similarity Network Evaluation[J]. Journal of Applied Mathematics, 2013 (2013). 